\title{
Cognitive load and knowledge sharing in Learning Networks
}

Citation for published version (APA):

Hsiao, A., Brouns, F., Kester, L., \& Sloep, P. (2013). Cognitive load and knowledge sharing in Learning Networks. Interactive Learnlng Environments, 21(1), 89-100. https://doi.org/10.1080/10494820.2010.548068

DOI:

$10.1080 / 10494820.2010 .548068$

Document status and date:

Published: 01/01/2013

Document Version:

Peer reviewed version

Document license:

CC BY-NC-ND

Please check the document version of this publication:

- A submitted manuscript is the version of the article upon submission and before peer-review. There can be important differences between the submitted version and the official published version of record. People interested in the research are advised to contact the author for the final version of the publication, or visit the DOI to the publisher's website.

- The final author version and the galley proof are versions of the publication after peer review.

- The final published version features the final layout of the paper including the volume, issue and page numbers.

Link to publication

\section{General rights}

Copyright and moral rights for the publications made accessible in the public portal are retained by the authors and/or other copyright owners and it is a condition of accessing publications that users recognise and abide by the legal requirements associated with these rights.

- Users may download and print one copy of any publication from the public portal for the purpose of private study or research.

- You may not further distribute the material or use it for any profit-making activity or commercial gain

- You may freely distribute the URL identifying the publication in the public portal.

If the publication is distributed under the terms of Article 25fa of the Dutch Copyright Act, indicated by the "Taverne" license above, please follow below link for the End User Agreement:

https://www.ou.nl/taverne-agreement

Take down policy

If you believe that this document breaches copyright please contact us at:

pure-support@ou.nl

providing details and we will investigate your claim.

Downloaded from https://research.ou.nl/ on date: 26 Apr. 2023 


\title{
Cognitive load and knowledge sharing in Learning Networks
}

\author{
Ya Ping (Amy) Hsiao , Francis Brouns, Liesbeth Kester and Peter Sloep \\ Centre for Learning Sciences and Technologies (CELSTEC), Open University of the \\ Netherlands
}

(Received $X X X$; final version received $X X X)$

\begin{abstract}
Learning Networks are online social networks designed to support non-formal learning; they are therefore particularly suitable for self-directed learners. In Learning Networks, learners need to acquire knowledge through knowledge sharing with other participants. However, without a support structure, learners have to organize knowledge sharing themselves and this could induce extraneous cognitive load. When working on complex learning tasks, this organizing process could have a detrimental effect on knowledge acquisition. To optimize cognitive load, we propose to use a particular type of collaborative learning, peer tutoring, as a support structure. Its mechanisms reduce, we argue, the extraneous load imposed by organizing knowledge sharing as well as induce germane load by directing the freed cognitive capacity to processes that contribute to knowledge acquisition.
\end{abstract}

Keywords: Learning Networks, cognitive load, knowledge sharing, peer tutoring

\section{Introduction}

By the nature of their learning needs, lifelong learners mainly direct their own learning

(Kester \& Sloep, 2009; Koper \& Tattersall, 2004; Sloep et al., 2007). To satisfy their needs, one had better move away from formal education and adopt non-formal learning. In principle, though not necessarily in practice, such settings are better equipped to accommodate the personalized learning goals of self-directed learners (Sloep, 2009). Non-formal learning is here defined as intentional learning based on personalized learning goals, exempt from externally imposed evaluation criteria and institutional supervision (Livingstone, 1999; Van Merriënboer, Kirschner, Paas, Sloep, \& Caniëls, 2009).

Learning Networks (LNs) are a particular kind of non-formal learning setting (Kester et al., 2006a; Sloep, 2009; Sloep et al., 2007). A LN is defined as an "online, social network that is designed to support non-formal learning in a particular domain" (Sloep, 2009, p.64). As Harasim and colleagues (Harasim, Hiltz, Teles, \& Turoff, 1995) already suggested over a decade ago, learning networks comprise groups of people who use learning resources to learn

\footnotetext{
*Corresponding author. E-mail: amy.hsiao@ou.nl
} 
together at the time, place, and pace that suits them best in ways appropriate to the task; in contrast with Harasim et al.'s rather liberal view, our focus is exclusively on self-directed learners (Harasim et al., 1995; Koper \& Sloep, 2002). Thus within our notion of a LN, learners have to take responsibilities to organize their own learning activities and to acquire knowledge from others to achieve their learning goals (Kester et al., 2007).

During the learning process, non-formal learners have the same needs as formal learners: they have content-based, procedural or meta-cognitive questions, or they want to compare their learning progress with that of others (Sloep, 2009). Based on their personalized learning goals, the learning needs of non-formal learners are usually more diverse and individualized than those of formal learners. In practice, it is impossible to rely on teaching staff alone to cater for their diverse learning needs (Sloep et al., 2007; Westera, De Bakker, \& Wagemans, 2009). To acquire knowledge, non-formal learners need to rely on other resources, such as their peers to share knowledge with.

During knowledge sharing, collaboration is a means to achieve reciprocal understanding between learners and to construct knowledge. LNs are designed as online social networks but this does not mean that peers will automatically share knowledge or that social interaction, in this case collaboration for knowledge construction, will magically occur (Kester et al., 2007). When working on a complex learning task, some learners may need to acquire knowledge from the others. For them, it is necessary to provide a support structure that not only allows knowledge exchanging to occur but also guides collaboration that contributes to knowledge construction. We first describe from a cognitive-load perspective how the human cognitive system deals with the knowledge sharing process when there is no support structure as in LNs (Paas, Renkl, \& Sweller, 2003a; Sweller, Van Merriënboer, \& Paas, 1998; Van Merriënboer \& Sweller, 2005). Based on the implications of cognitive load 
theory (CLT), we propose peer tutoring as a support structure to assist knowledge sharing and promote knowledge acquisition.

\section{Cognitive load theory}

According to CLT the human cognitive architecture consists of a limited working memory and an unlimited long-term memory (Paas et al., 2003a). Working memory processes new information that is then stored in the form of schemata in long-term memory (Sweller et al., 1998). When working memory has to organize, contrast or compare information elements, only two or three new interactive elements can be processed simultaneously (Paas et al., 2003a).

When performing a particular task, the load that is imposed by this task on the learner's cognitive system is defined as cognitive load (Paas, Renkl, \& Sweller, 2004). CLT distinguishes three types of cognitive load: intrinsic, extraneous and germane load. Intrinsic load refers to the intrinsic difficulty or complexity of a learning task; it is often measured as the number of interactive information elements in a learning task (Sweller, 2006). Extraneous and germane load are associated with the task design: extraneous load is imposed by an ineffective design that forces learners to carry out unnecessary cognitive processing; germane load is imposed by an effective design that engages learners in the task itself (Sweller et al., 1998; Van Gog \& Paas, 2008). Intrinsic, extraneous, and germane load are additive (Paas et al., 2003a; Sweller et al., 1998) and the total cognitive load should not exceed working memory limits. To contribute to effective learning, the central pedagogical principle of CLT is to design instruction that aligns with the human cognitive architecture (Paas, Tuovinen, Tabbers, \& Van Gerven, 2003b; Van Gog \& Paas, 2008). This principle has guided many early researchers to design instruction that reduces extraneous load, especially when a task is high in intrinsic load (Van Gog \& Paas, 2008; Van Merriënboer \& Sweller, 2005). 
Recent CLT-related research aims not only at reducing extraneous load (that does not contribute to or even hinders learning) but also to increasing germane load (that fosters learning) (Paas et al., 2003a; Sweller et al., 1998; Van Gog \& Paas, 2008; Van Merriënboer \& Sweller, 2005). When extraneous load is reduced, working memory capacity is freed up. However, merely freed-up working memory capacity does not guarantee better learning effects. To achieve this, an instructional design should further direct learners to invest their freed-up working memory capacity in activities that contribute to knowledge acquisition (i.e. in germane load inducing activities) (De Jong, 2010; Sweller et al., 1998; Van Gog \& Paas, 2008).

To assess the cognitive effect of an instructional design, it is necessary to measure cognitive load during the learning and/or test phases. The most commonly used measure is based on learners' subjective judgement on a unidimensional rating scale (Van Gog \& Paas, 2008). What learners report on this rating scale is called "mental effort", which refers to how much cognitive capacity actually has been allocated to accomplishing a learning task (Paas, 1992; Paas et al., 2003b). However, this mental effort measure does not distinguish between the three types of cognitive load (Beckmann, 2010; De Jong, 2010). To know whether an instructional design is effective in reducing extraneous load or increasing germane load, the conventional way is to calculate the learning efficiency. This is done by combining during the test phase mental effort measures with performance measures (Paas \& Van Merriënboer, 1993; Van Gog \& Paas, 2008). Thus, a high learning efficiency combines a high performance score with a low mental effort investment whereas a low learning efficiency combines a low performance score with a high mental effort investment. If an instructional design aims to reduce extraneous load, the efficiency measure should take into account the perceived mental effort during the learning phase. If the aim is to both reduce extraneous load and increase 
germane load, the perceived mental effort during the test phase is used as part of the efficiency measure (Van Gog \& Paas, 2008).

We believe that CLT provides us a framework to describe and gauge the load imposed by knowledge sharing in LNs where no support structure is available. More specifically, to understand how to design a support structure in LNs, CLT can help us explain how peer tutoring should be deployed to optimize cognitive load during knowledge sharing by pointing out how to reduce the extraneous load as well as to increase the germane load of knowledge sharing.

\section{Cognitive load during knowledge sharing}

Successful online knowledge sharing depends on whether two parties (i.e. one that possesses knowledge and the other that acquires knowledge) can communicate and collaborate with each other. With regards to effective online collaborative learning, Dillenbourg and Schneider (1995) proposed that three aspects must be considered: group composition, communication media and task features. We first describe why knowledge sharing becomes ineffective when the first two aspects are not supported in LNs. We will defer the discussion of task features to the next section.

Ideally, learners who are interested in a particular domain can participate in LNs without entry requirements. Thus, participants in LNs form heterogeneous groups: they are likely to have different learning purposes, academic backgrounds, competency levels and experiences, as well as knowledge about the learning topics. This heterogeneity can ensure lively knowledge sharing in a community (Kester \& Sloep, 2009). However, it also imposes extraneous load when learners want to find a relevant collaborator. Since LNs lack the social structure of a class, learners in LNs do not necessarily know each other nor do they have a common learning history (Van Rosmalen et al., 2006). Without a support structure for finding suitable knowledge sharers, learners need to allocate cognitive resources to explore what 
other participants are in the LN, to interact with them, and finally to find out who are suited to exchange knowledge with. Since these activities i) are not directly related to learning itself but to the learning environment, ii) detract from learning rather than facilitate it, they increase the extraneous load.

LNs are online networks. Therefore, learners rely on online communication to interact with others. Online communication, whether synchronous or asynchronous, differs from direct face-to-face communication in its cognitive load demands. In face-to-face settings, a learner can anticipate the needs of her peer, get feedback on whether her peer receives and understands the information, as well as check whether they both are in agreement through both verbal and non-verbal messages (Kiesler, Siegel, \& McGuire, 1988). In online communication, these features are missing to a larger or smaller extent, and this leads to difficulties in finding a common basis for mutual understanding (Cress \& Hesse, 2006). Moreover, in synchronous online communication, two learners need to meet at the same time, which requires extra planning; in asynchronous online communication, learners have make the extra effort of putting down their thoughts into written texts, et cetera. This too, one may argue, contributes to an increased extraneous load.

To sum up, without a support structure that deals with heterogeneous group composition and online communication, knowledge sharing imposes additional extraneous load because extra cognitive resources have to be devoted to finding a suitable collaborator and finding out how best to communicate with others online. As according to CLT the different kinds of cognitive load add up and there is an upper limit to the available cognitive load, these organizing and maintaining activities diminish the cognitive capacity available for knowledge acquisition itself. 


\section{Task complexity and cognitive load}

The third (and final) aspect that affects online collaborative learning concerns the task features: tasks should be designed for collaboration (Dillenbourg \& Schneider, 1995; Kirschner, Beers, Boshuizen, \& Gijselaers, 2008b). In formal educational settings, this can be done by using pre-designed tasks to initiate collaboration among learners. Because of the non-formal character of learning in LNs, there are no mandatory learning tasks. Non-formal learners choose their own learning actions, which are based on their individual plans. In these kinds of cases, collaboration is initiated by the complexity of the learning 'task' or action (rather than by the task design itself).

According to CLT, task complexity depends on element interactivity (Sweller, 2006). A task is complex if many task elements interact and cannot be understood in isolation; a task is simple if few task elements interact or can be understood and learned independently of each other. Levels of element interactivity determine the level of intrinsic load of a task, because human working memory can only simultaneously process a limited number of interacting information elements (Paas et al., 2003a; Sweller, 2006). When working on complex learning tasks, a learner's limited working memory has to process many interacting elements, which causes a high intrinsic load. To have more cognitive resources available, a learner may seek recourse to knowledge sharing, that is, to be helped out by others.

According to CTL, two cognitive benefits of knowledge sharing explain why learners want to collaborate. First, it is assumed that a task's intrinsic load can be shared among group members, which frees up individual working memory capacity (Kirschner, Paas, \& Kirschner, 2008a, 2009b). Second, a group can be considered to be an information processing system that consists of multiple individual working memories. According to this argument, the thus created joint working memory has more processing capacity and can therefore deal with more complex learning actions than can each individual working memory (Kirschner et al., 2008a; Kirschner, Paas, \& Kirschner, 2009a). However, these cognitive benefits can only 
work well when collaborating learners know how to share knowledge with each other. As argued, without a support structure learners need to allocate extra cognitive resources to organizing and maintaining knowledge sharing. Thus, it could be detrimental to learning if a learner has to simultaneously deal with the high intrinsic load of complex learning actions and the extraneous load of knowledge sharing.

\section{Optimizing cognitive load during knowledge sharing}

To overcome the negative effects of i) the need to find a collaborator, ii) to communicate online rather than face to face, iii) not knowing how to collaborate and share knowledge, we propose to use a technology-enhanced form of peer tutoring (PT). The technology used consists of a mechanism that guarantees that with relatively little effort an optimal knowledge-sharing match is made. We first introduce PT, discuss its positive effects on learning and then explain how the PT-system works in the context of LNs. With this in mind we discuss how use of our technology-enhanced form of PT in LNs optimizes cognitive load by (i) reducing extraneous load, (ii) increasing germane load and (iii) spreading high intrinsic load of the task among tutor and tutee.

PT is defined as "people from similar social groupings who are not professional teachers, helping each other to learn, and learning themselves by teaching”(Topping, 1996, p.322). The method is to stimulate learners to discuss their learning and negotiate meaning with each other: they clarify their understanding of a topic and uncover gaps in or misunderstandings of the material (King, 1997, 1998, 2002). Various studies report that the students who learned with a PT structure achieved higher learning outcomes (Fantuzzo, Riggio, Connelly, \& Dimeff, 1989; Gyanani \& Premlata, 1995; King, Staffieri, \& Adelgais, 1998). With a PT structure, students were more engaged in learning activities and knowledge sharing and less engaged in structuring these activities (Fantuzzo et al., 1989; Greenwood, Delquadri, \& Hall, 1989). 
As for tutees, they felt that peer tutors understood their problems better and were more interested in the communication process than staff tutors (Moust \& Schmidt, 1994). This translates to advantages for the tutee: the latter participates more actively and interactively in the learning process and gets more immediate feedback (Topping, 1996). Importantly, the advantages of using PT is that it is not only beneficial for tutees who initially want to acquire knowledge from tutors but also for peer tutors who share knowledge with tutees (Gyanani \& Premlata, 1995; Topping, 1996). Topping (1996) attributed the advantages of being a peer tutor to an old saying "to teach is to learn twice". Because tutoring is itself a motive for peer tutors to reorganize their existing knowledge, they pay more attention to the task and therefore increase more cognitive participation in learning.

Benefits of using PT in non-formal online learning environments have been found by recent studies of Van Rosmalen et al. (2008a; 2008b) and De Bakker et al. (2008): evaluation by staff tutors indicated that the quality of the answers provided by peer tutors was good (Van Rosmalen et al., 2008a). As peer tutors, learners indicated that investigating time in answering others' questions improved their knowledge and understanding (Van Rosmalen et al., 2008a). Similar results were also found by De Bakker (2008): students who used a synchronous peer tutoring tool were positive about helping each other in answering questions on a specific topic. In an asynchronous PT environment, students were willing to practice more with peers than with the teacher and they felt that they benefited from answering each other's questions (Hsiao, 2009).

From previous PT research, we found three common mechanisms: a peer tutor selection system, role specifications and interaction structures (King, 1997; King et al., 1998; Topping, 1996; Van Rosmalen et al., 2008a). We next discuss how these three mechanisms of PT would optimize cognitive load during knowledge sharing. 


\section{Peer tutor selection}

In traditional PT, the teacher usually relies on instructional considerations to assign peer tutors. In LNs, learners have to find peer tutors by themselves and, as argued, this imposes extraneous load because they do not know what peers are suitable as tutors for sharing knowledge with about a specific topic. To avoid this, a technology-enhanced peer tutor selection system, which as it were replaces the teachers, is used. Indications that such a system works are provided by Van Rosmalen and colleagues: when they arranged for peer tutors to be automatically matched to peers on the basis of several criteria, more questions were answered in a shorter period of time than when peer tutors were randomly assigned (Van Rosmalen et al., 2008a). On the one hand, this suggests that less extraneous load is imposed on the peers who collaborated with peer tutors to which selection criteria had been applied; on the other hand, when cognitive resources were directed to knowledge acquisition (i.e. question-answer behaviour) it suggests that participants were likely to experience germane load.

Van Rosmalen et al. (2008b) built a software application that, on the basis of a question asked by a learner (tutee), finds and invites a few suitable, potential tutors. Once they accept the invitation, they become de-facto tutors. Van Rosmalen et al. (2008b) created groups of 3 tutors who via a wiki interacted with the tutee, but other arrangement are possible. The software used several selection criteria to arrive at the best possible tutor-tutee-match in view of the question that was posed. They are content competency, tutor competency, availability, and eligibility (Kester et al., 2006b; Van Rosmalen et al., 2008b). Content competency ensures that the peer tutor is knowledgeable on the subject. Tutor competency ensures that the peer tutor is able to transfer knowledge in an appropriate manner. Eligibility ensures that a peer tutor is selected who is at a learning level similar to that of the tutee. Availability is not only based on actual availability in personal calendar data, but also considers the past workload to prevent that a particular learner is called upon too often. 
Jointly, these criteria ensure that a tutee is paired with the most suitable tutor. Use of this tutor-finding system instead of having to go out and find a tutor oneself translates into a reduced extraneous load for the tutee. Use of the system also reduces the extraneous load for the peer tutor as the system guarantees a match with a receptive tutee at little effort (particularly the availability criterion does so). What is more, the system also induces germane load because only the most suitable tutor knows best how to transmit knowledge to her tutee in view of her content competency, tutor competency and eligibility (e.g., explanation, elaboration and clarification skills).

\section{Role specifications}

Role specifications include assigning roles and role tasks. When using PT-system as a support structure, the roles of tutor or tutee are assigned when knowledge sharing starts and this can decrease extraneous load. With role tasks, the extraneous load can be reduced because tutors and tutees know how to function when sharing knowledge. If role tasks are well specified, they can also increase germane load. For example, tutors are told to retrieve their prior knowledge, integrate it into the tutee's question and explain it to the tutee; tutees are told to negotiate meaning if they do not understand tutors.

When knowledge sharing works well, role tasks can optimize high intrinsic load of the learning action by making tutor and tutee become cognitive resources for each other. For example, a tutee relies on her tutor to check her understanding of the explanations. A tutor reflects on her knowledge when reviewing the explanations of her tutee from a different perspective. As already argues, this mutual cognitive reliance enlarges individual working memory capacity into a larger group working memory capacity (Kirschner et al., 2008a, 2009b): they profit from the processing effort of others, they help each other to remember or recall certain aspects of their interaction history and learning actions, and they prompt each other for additional information (King, 1998). With this larger working memory capacity, 
tutor and tutee are better able to deal with high intrinsic load of the learning action (King, 1998; Kirschner et al., 2008a, 2009b).

\section{Interaction structures}

Within face-to-face PT, students can interact with each other through verbal and non-verbal communication. Traditionally, PT and collaborative learning apply interaction structures to make sure that the expected communication and collaboration between students will happen (King, 1997, 1998, 2002; Kirschner et al., 2008b). Thus, PT usually includes approaches such as supportive communication, explanation and elaboration, asking questions and sequencing questions, et cetera to structure interaction (King, 1997, 1998, 2002). These interaction structures scaffold the collaboration process of knowledge sharing and guide learners to clarify, organize and elaborate their ideas. They require extra cognitive processing but at the same time help knowledge acquisition (i.e. germane load).

PT in LNs, however, differs from traditional PT settings in at least two ways. First, to start knowledge sharing in LNs, learners need a support structure that allows them to communicate with each other. As argued, learners in LNs rely on online communication to interact with each other and this causes additional extraneous load. When applying PT in LNs, providing learners with a system that structures interaction facilitates communication at least minimizes the extent of extraneous load. The PT system discussed does so by providing a wiki-based communication system (Van Rosmalen et al., 2008a; Van Rosmalen et al., 2008b). A wiki is an editable website that allows people to work collaboratively and its inherent characteristics naturally support group processes and knowledge construction (Cole, 2009).

Second, when considering to the non-formal characteristic of LNs, we cannot structure the interaction or collaboration among learners because this would go against their self-directness. Thus, we transform the notion of the interaction structure into an interaction 
tool that supports learners to communicate and collaborate for knowledge sharing. Again, the wiki that was used as an interaction tool, included an instruction that specified role tasks, expected interaction and the process of knowledge sharing (Van Rosmalen et al., 2008a; Van Rosmalen et al., 2008b). When knowledge sharing is supported with such an interaction tool, extraneous load resulting from online communication and maintaining collaborative interaction can be reduced and this frees up working memory capacity. In addition, using a wiki as an interaction structure contributes to progressive problem-solving, evolutionary knowledge construction, explaining diverse and contradictory ideas, etc.(Fountain, 2005). These activities have pedagogical benefits because they promote learning itself.

\section{Conclusion}

We argued that knowledge sharing in Learning Networks (LNs) would result in additional extraneous load when there is no proper support structure that would guide learners to go through the knowledge sharing process. The impact of increased extraneous load becomes particularly detrimental when learners work on complex learning actions that by their nature have a high intrinsic load.

Numerous studies have applied the insights of Cognitive Load Theory (CLT) for teacher-lead instruction, particularly to solve problems of a high extraneous load. To the best of our knowledge there are none that address the cognitive aspects of learners in non-formal learning environments, environments without guidance of the teacher such as LNs. If anything, CLT seems to predict that in LNs with its self-directed learners and lack of specifically designed learning tasks, extraneous load is increased.

Similarly CLT has been successfully used to underpin the benefits of collaborative learning, which reside in the reduction of intrinsic load and the expansion of total working memory. These benefits, however, do not seem to apply in the case of LNs, as they rely on tasks that have been designed with collaboration and the availability of teachers in mind. 
Yet in this paper, we argue that with a proper use of technology, one that fits the situation of online learning in Learning Networks, a similar reduction of extraneous load and increase of germane load may be achieved. The key to unlocking this potential is (collaborative) peer tutoring (PT).

Previous studies of PT have shown its various beneficial effects on the learning process. To assist learning through knowledge sharing in LNs, we argued that the mechanisms of traditional PT have to be transformed and refashioned for the online learning environment that a Learning Network constitutes. Our analysis focused on three mechanisms of PT that jointly would optimize the cognitive load identified during knowledge sharing. A software-based peer tutor selection system helps finding the most suitable knowledge sharer and thus decreases extraneous load and increases germane load. Role specifications specify which role a learner takes, inform tutor and tutee how to function their role tasks, and help tutor and tutee have more cognitive resources to deal with the high intrinsic load of the learning action. By supporting communication and collaboration of knowledge sharing, an interaction tool such as a wiki reduces extraneous load and directs learners to invest mental effort in processes that contribute to learning causing so-called germane load. Please note that we proposed PT as an ad hoc support structure, to cater for self-organized knowledge sharing, instead of as an instruction intervention used in the conventional way of PT or collaborative learning.

Although ample empirical evidence exists about the effectiveness of the peer-tutor matching system and its associated wiki, these results have been phrased in such terms as user satisfaction, experts assessment of answer quality, responsiveness of the system, quality of the matching mechanism, etc. (Van Rosmalen, 2008; Van Rosmalen et al., 2008a.) Our present argument is different. It is about the feasibility of Learning Networks qua learning environments for non-formal learning. Although arguments pro or con a peer-tutoring 
system's effectiveness and efficiency are relevant to this, they do not shed any light on a comparison of such an environment with more traditional, teacher-led, formal learning environments. The vehicle of CLT provides a means for making such a comparison.

On the face of it, CLT seems to indicate that novel, student-led ('self-organised'), non-formal learning environments as LNs are inferior to traditional, teacher-led formal learning environments. As our analysis showed, such a superficial analysis may be quite misleading. Arguments can be found, using CLT, that indicate that LNs empowered by software systems that support and facilitate peer-tutoring are quite capable of having a low extraneous load and a high germane load. Of course, only empirical evidence can confirm (or disconfirm) these a priori findings.

That is why, in future studies, we intend to verify the arguments in this article. First, we will check our assumption that without a support structure knowledge sharing on complex learning actions has detrimental effects on learning. We will use an experimental design that investigates whether there is an interaction effect from different support structures and different levels of task complexity. Second, an empirical study will be conducted that investigates whether peer tutoring can indeed help optimize cognitive load in knowledgesharing contexts. Although, as indicated, the verdict is still out on whether the arguments given in this paper can withstand the scrutiny of empirical testing, in our view this paper has established that CLT can be sensibly and profitably used in the contexts of self-organised, self-direct, non-formal learning such as found in LNs. 


\section{References}

Beckmann, J. F. (2010). Taming a beast of burden - On some issues with the conceptualisation and operationalisation of cognitive load. Learning and Instruction, 20(3), 250-264.

Cole, M. (2009). Using Wiki technology to support student engagement: Lessons from the trenches. Computers \& Education, 52(1), 141-146.

Cress, U., \& Hesse, F. (2006). The social complexity in establishing and sharing information resources. In J. Elen \& R. E. Clark (Eds.), Handling complexity in learning environments: Theory and research (pp. 67-87). Oxford, UK: Elsevier Ltd.

De Bakker, G., Sloep, P., \& Jochems, W. (2008). Towards a system for allocated peer tutoring via instant messaging: a pilot study. Paper presented at the ALT-C conference 2008.

De Jong, T. (2010). Cognitive load theory, educational research, and instructional design: some food for thought. Instructional Science, 38(2), 105-134.

Dillenbourg, P., \& Schneider, D. (1995). Collaborative learning and the Internet. Retrieved May 26, 2009, from http://tecfa.unige.ch/tecfa/research/CMC/colla/iccai95_1.html

Fantuzzo, J. W., Riggio, R. W., Connelly, S., \& Dimeff, L. (1989). Effects of Reciprocal Peer Tutoring on Academic Achievement and Psychological Adjustment: A Component Analysis. Journal of Educational Psychology, 81(2), 173-177.

Fountain, R. (2005). Wiki pedagogy. Retrieved March 31th, 2010, from http://profetic.org/dossiers/article.php3?id_article=969.

Greenwood, C. R., Delquadri, J. C., \& Hall, R. V. (1989). Longitudinal Effects of Classwide Peer Tutoring. Journal of Educational Psychology, 81, 371-383.

Gyanani, T. C., \& Premlata, P. (1995). Effects of Peer Tutoring on Abilities and Achievement Contemporary Educational Psychology, 20, 469-475.

Harasim, L., Hiltz, R., Teles, L., \& Turoff, M. (1995). Learning Networks: A field guide to teaching and learning online. Cambridge: MIT Press.

Hsiao, Y. P. (2009, September 18th, 2009). Interactief Chinees leren [Interactive Chinese learning]. Retrieved November 15th, 2009, from http://www.surfspace.nl/nl/Praktijkvoorbeelden/Pages/INTERACTIEFCHINEESLER EN.aspx

Kester, L., \& Sloep, P. (2009). Knowledge dating and knowledge sharing in Ad-Hoc Transient Communities. In R. Koper (Ed.), Learning Network Services for Professional Development (pp. 43-56). Berlin and Heidelberg: Springer-Verlag.

Kester, L., Sloep, P., Brouns, F., Van Rosmalen, P., De Vries, F., De Croock, M., et al. (2006a, 26-28 February). Enhancing social interaction and spreading tutor responsibilities in bottom-up organized learning networks. Paper presented at the Proceedings IADIS Conference Web Based Communities, San Sebastian, Spain.

Kester, L., Sloep, P., Van Rosmalen, P., Brouns, F., Koné, M., \& Koper, R. (2006b). Facilitating community building in Learning Networks through peer tutoring in ad hoc transient communities. International Journal of Web based Communities, 3(2), 198-205.

Kester, L., Van Rosmalen, P., Sloep, P., Brouns, F., Koné, M., \& Koper, R. (2007). Matchmaking in Learning Networks: Bringing Learners Together for Knowledge Sharing. Interactive Learning Environments, 15(2), 117-126.

Kiesler, S., Siegel, J., \& McGuire, T. W. (1988). Social psychological aspects of computermediated communication (Reprint). In I. Greif (Ed.), Computer-supported cooperative work: a book of readings (pp. 657-682). San Mateo: Morgan Kaufmann Publishers Inc. 
King, A. (1997). ASK to THINK-TEL WHY: A model of transactive peer tutoring for scaffolding higher level complex learning. Educational Psychologist, 32(4), 221-235.

King, A. (1998). Transactive Peer Tutoring: Distributing Cognition and Metacognition. Educational Psychology Review, 10(1), 57-74.

King, A. (2002). Structuring peer interaction to promote high-level cognitive processing. Theory into Practice, 41(1), 33-39.

King, A., Staffieri, A., \& Adelgais, A. (1998). Mutual peer tutoring: Effects of structuring tutorial interaction to scaffold peer learning. Journal of Educational Psychology, 90(1), 134-152.

Kirschner, F., Paas, F., \& Kirschner, P. A. (2008a). Individual versus group learning as a function of task complexity: An exploration into the measurement of group cognitive load. In J. Zumbach, N. Schwartz, T. Seufert \& L. Kester (Eds.), Beyond knowledge: The legacy of competence (pp. 21-28): Springer.

Kirschner, F., Paas, F., \& Kirschner, P. A. (2009a). A cognitive-load approach to collaborative learning: United brains for complex tasks. Educational Psychology Review, 21, 31-42.

Kirschner, F., Paas, F., \& Kirschner, P. A. (2009b). Individual and group-based learning from complex cognitive tasks: Effects on retention and transfer efficiency. Computers in Human Behavior, 25(2), 306-314.

Kirschner, P. A., Beers, P. J., Boshuizen, H. P. A., \& Gijselaers, W. H. (2008b). Coercing shared knowledge in collaborative learning environments. Computers in Human Behavior, 24(2), 403-420.

Koper, R., \& Sloep, P. B. (2002). Learning Networks: connecting people, organizations, autonomous agents and learning resources to establish the emergence of effective lifelong learning: Education Technology Expertise Centre (OTEC), Open University of the Netherlands.

Koper, R., \& Tattersall, C. (2004). New directions for lifelong learning using network technologies. British Journal of Educational Technology, 35(6), 689-700.

Livingstone, D. W. (1999). Exploring the Icebergs of Adult Learning: Findings of the First Canadian Survey of Informal Learning Practices. The Canadian Journal for the Study of Adult Education, 13, 49-72.

Moust, J. H. C., \& Schmidt, H. G. (1994). Facilitating small-group learning: a comparison of student and staff tutors' behavior. Instructional Science, 22, 287-301.

Paas, F. (1992). Training Strategies for Attaining Transfer of Problem-Solving Skill in Statistics: A Cognitive-Load Approach. Journal of educational psychology, 84(4), 429-434.

Paas, F., Renkl, A., \& Sweller, J. (2003a). Cognitive Load Theory and Instructional Design: Recent Developments. Educational Psychologist, 38(1), 1-4.

Paas, F., Renkl, A., \& Sweller, J. (2004). Cognitive Load Theory: Instructional Implications of the Interaction between Information Structures and Cognitive Architecture. Instructional Science, 32, 1-9.

Paas, F., Tuovinen, J., Tabbers, H., \& Van Gerven, P. (2003b). Cognitive Load Measurement as a Means to advance Cognitive Load Theory. Educational Psychologist, 38(1), 6371.

Paas, F., \& Van Merriënboer, J. (1993). The Efficiency of Instructional Conditions: An Approach to Combine Mental Effort and Performance Measures. Human Factors, 35(4), 737-743.

Sloep, P. (2009, June, 11-13, 2008). Fostering Sociability in Learning Networks through AdHoc Transient Communities. Paper presented at the Computer-Mediated Social Networking, Dunedin, New Zealand. 
Sloep, P., Kester, L., Brouns, F., Van Rosmalen, P., De Vries, F., De Croock, M., et al. (2007, 14-16 March). Ad Hoc Transient Communities to Enhance Social Interaction and Spread Tutor Responsibilities. Paper presented at the The Sixth IASTED International conference Web-Based Education, Chamonix, France.

Sweller, J. (2006). How the human cognitive system deals with complexity. In J. Elen \& R. E. Clark (Eds.), Handling complexity in learning environments: Theory and research (pp. 13-25). Oxford, UK: Elsevier.

Sweller, J., Van Merriënboer, J., \& Paas, F. (1998). Cognitive Architecture and Instructional Design. Educational Psychology Review, 10(3), 251-296.

Topping, K. J. (1996). The effectiveness of peer tutoring in further and higher education: A typology and review of the literature. Higher Education, 32(3), 321-345.

Van Gog, T., \& Paas, F. (2008). Instructional Efficiency: Revisiting the Original Construct in Educational Research. Educational Psychologist, 43(1), 16-26.

Van Merriënboer, J., Kirschner, P., Paas, F., Sloep, P., \& Caniëls, M. (2009). Towards an integrated approach for research on lifelong learning. Educational Technology Magazine, 49(3), 3-15.

Van Merriënboer, J., \& Sweller, J. (2005). Cognitive Load Theory and Complex Learning: Recent Developments and Future Directions. Educational Psychology Review, 17(2), 147-199.

Van Rosmalen, P. (2008). Supporting the tutor in the design and support of adaptive elearning. Open University, Heerlen.

Van Rosmalen, P., Sloep, P., Brouns, F., Kester, L., Berlanga, A., Bitter, M., et al. (2008a). A model for online learner support based on selecting appropriate peer tutors. Journal of Computer Assisted Learning, 24(6), 483-493.

Van Rosmalen, P., Sloep, P., Brouns, F., Kester, L., Koné, M., \& Koper, R. (2006). Knowledge matchmaking in Learning Networks: Alleviating the tutor load by mutually connecting Learning Network users. British Journal of Educational Technology, 37(6), 881-895.

Van Rosmalen, P., Sloep, P., Kester, L., Brouns, F., De Croock, M., Pannekeet, K., et al. (2008b). A learner support model based on peer tutor selection. Journal of Computer Assisted Learning, 24(1), 74-86.

Westera, W., De Bakker, G., \& Wagemans, L. (2009). Self-arrangement of fleeting student pairs: a Web 2.0 approach for peer tutoring. Interactive Learning Environments, 17(4), 341-349. 